\title{
norden
}

Nordic Council of Ministers

Ved Stranden 18

DK-1061 Copenhagen K

www.norden.org

NORDISKE ARBEJDSPAPIRER

NORDIC WORKING PAPERS

\section{Operationalizing Equity in the 2015 Agreement}

Report from Nordic-Belgian Workshop on 24.-25.10.2013

in Stockholm, Sweden

Steffen Kallbekken and Håkon Sælen

NA2013:928

http://dx.doi.org/10.6027/NA2013-928

This working paper has been published with financial support from the Nordic Council of Ministers. However, the contents of this working paper do not necessarily reflect the views, policies or recommendations of the Nordic Council of Ministers. 



\title{
Operationalizing Equity in the 2015 Agreement
}

\section{Report from Nordic-Belgian Workshop on October 24-25 2013}

\author{
Steffen Kallbekken and Håkon Sælen \\ CICERO Center for International Climate and Environmental Research - Oslo
}

On October 24-25 2013 the Nordic Council of Ministers and the Government of Belgium invited selected representatives of Parties, NGOs, and academia to a workshop on operationalizing equity in the context of the 2015 agreement, with particular reference to the negotiations track from Warsaw to Paris. The first day was devoted to academic presentation and follow-up discussions. The second day featured a roundtable discussion between negotiators under Chatham House Rules. This report is not exhaustive, but focuses on key ideas and questions that arose during the discussions. The second day is prioritized, as presentations from the first day are available online. No attempt was made to arrive at consensus at the workshop, only to raise important issues and debate constructive ideas. Hence, this report should be read as an inventory of ideas that received support from at least some workshop participants, not as a summary of consensual conclusions. Any biases or omissions should be attributed to the rapporteurs.

The report is divided into four main parts which were discussed during the second day: 1) The scope and role of equity in the 2015 agreement, 2) differentiation, 3) indicators, and 4) review and timing.

\section{The scope and role of equity}

The workshop aimed to focus on implementing equity in a practical way, rather than having abstract, theoretical discussions. Participants recognized that there are multiple interpretations of equity, and that these correlate with national interests. It was said that equity is in the eye of the beholder, however, many envisioned a role for objective indicators informing the political debate. It was suggested we do not need to define equity up front but rather look at whether it is implemented in the outcome of negotiations, and that we should aim for a result that is perceived as "fair enough" by all, if not perceived as perfectly equitable by any. Furthermore, it was stressed that the equity of the outcome is not only about the equity of mitigation commitments (the term was used interchangeably with pledges and offers), because action on climate change goes beyond mitigation activities, as adaptation and means of implementation will also play an important role in coping with the impacts. Impacts that will most of all affect the most vulnerable. 


\section{norden}

Nordic Council of Ministers

federal public service

HEALTH, FOOD CHAIN SAFETY

AND ENVIRONMENT

\section{Equity and adaptation}

Adaptation in relation to equity has received relatively little attention to date, but emerged as a core topic at the workshop. People around the world were said to be mainly thinking about impacts and adaptation, and adaptation should be part of the new agreement. It was argued over whether successful adaptation should be the ultimate objective of the UNFCCC.

Adaptation and mitigation should be considered together, as less mitigation means more need for adaptation, but it was also pointed out that the incentive structure is very different for the two, particularly in relation to the private sector. Mitigation is primarily a global challenge, while adaptation can arguably be successfully done locally, if sufficient resources are made available.

It was suggested that equity in relation to adaptation is mostly about finance, and as the architecture for adaptation finance is already in place, this becomes largely an issue of the adequacy of funding. Adaptation finance could also serve to incentivize participation in the new agreement.

A specific proposal was a process where mitigation commitments would be aggregated, then the additional global adaptation cost (relative to 2 degrees warming) would be calculated, then Parties would submit new commitments on how to cover adaptation costs. A higher temperature rise would thus imply higher financial commitments for adaptation. The feasibility of calculating global adaptation costs was questioned.

\section{Equity and adequacy}

The issue of equity goes beyond the notion of a fair distribution of the burden. One can conceive of a regime where efforts are perceived to be fairly distributed among Parties but that leads us to a 6 degrees warming. Hence, the outcome itself is not equitable unless efforts aggregate to sufficient ambition. Fears were expressed that national determination of commitments does not ensure adequate ambition, and that national circumstances or lack of perceived equity will be used as an excuse not to act. It was noted that the adequacy of mitigation commitments is distinct from the adequacy of the plan to increase these commitments over time.

\section{Equity and means of implementation}

Both mitigation and adaptation actions need finance, technology and capacity building to be implemented. Equity in means of implementation was not discussed at length but some noted the need to further elaborate on this issue.

\section{Differentiation of mitigation commitments}

The key equity principle in the convention is Common But Differentiated Responsibility and Respective Capabilities (CBDR-RC). The issue of defining which elements of commitments should be common (e.g. reporting) and which should be differentiated (e.g. mitigation targets) is therefore a core issue. Differentiation of mitigation targets means matching Parties with commitments. The matching process can be based on categories of Parties or categories of commitments, categories for both, or no 


\section{nordan}

Nordic Council of Ministers

federal public service

HEALTH, FOOD CHAIN SAFETY AND ENVIRONMENT

categorization. A categorization of countries could depart from the current annexes, introducing differentiation within the annexes with the possibility of overlap between them. Categories of commitments include QELROs and intensity targets (relative to GDP or population). A pledge-and-review process, where commitments are nationally determined, can render the annexes less relevant, relying instead to a great extent on self-differentiation. With such a process, important questions are how to ensure equity is taken into account, and how much prescription is needed before starting the process. Ideas were presented on how to discipline this self-differentiation. Objective indicators may play an important role in such a process.

\section{Indicators}

There was little support for a formula for defining equity, but there was broad agreement that quantified indicators could play a more-or-less prescriptive role in disciplining pledges. The interaction between indicators and pledges is important. In particular, Parties should use indicators to ensure internally and show to others that their pledge meets their responsibility and capability. Indicators would be useful for assessing whether a pledge is fair relative to commitments of others, and relative to the required aggregate effort.

A central topic was the feasibility of and need for agreeing on a common set of indicators. Three different suggestions were discussed particularly. The most top-down option is an "equity reference framework" consisting of a basket of indicators that would be calculated for all countries. The most bottom-up approach would be to leave it to Parties to choose which indicators to use to present their commitment as fair. An intermediate suggestion is to agree to a finite, official set of indicators, but allow each Party to decide which of these indicators to disclose. A decision not to include a certain indicator would then be explicit and could spur a need for justification/explanation why that indicator was not included. Many thought it difficult to reach agreement on a common set of indicators, and the need for up-front agreement could cost precious negotiating time. On the other hand, it was suggested that if all delegations were to submit five indicators, the lists would likely overlap significantly, making agreement on a common list feasible. In response, it was noted that if Parties' lists of preferred indicators overlap, there is less need for agreement on a common set because Parties might pick the same ones if left to their own devices. Inviting Parties to use indicators of their own choosing, and do so in a transparent manner would be a realistic option. This might make comparisons across Parties more difficult, but would make agreement under time pressure easier in the first place, relative to having a common set. In addition, agreement on necessary up-front information related to the commitments and its full delivery could also enable use of many indicators ex-post. This option leads to questions of which indicators Parties might legitimately invoke. It was suggested giving Parties the right to demand that another specific Party reports a specific indicator. An alternative suggestion is that if one country uses a given set of indicators, it must accept that other countries use the same set. 


\section{nordan}

Nordic Council of Ministers

federal public service

HEALTH, FOOD CHAIN SAFETY AND ENVIRONMENT

The need for clarity and simplicity was stressed as key for indicators' usefulness for both Parliamentarians and civil society. It is also important that the system does not become too demanding for developing country Parties. It was suggested that Parties might request an official expert group to calculate indicators on their behalf. An expert group might also contribute to assessing submissions on which indicators to include if agreement on a common set is pursued. Practical difficulties with the use of expert groups were noted. They would require time, and a clear mandate from the Parties.

\section{Review and timing}

Ex-ante review of pledges has been suggested as a way to 1) discipline national determination of commitments, 2) aid understanding of others' offers, 3) test if pledges would fit with the accounting system, and 4) induce ratcheting up of pledges. Pledges would be reviewed in terms of aggregate adequacy in relation to the 2 degree goal and relative fairness, as well as the principles of the convention. For the latter purpose, indicators can play a role. A multilateral assessment (i.e. within the FCCC) was suggested, but civil society will likely also contribute.

A challenge with the pledge and review process is that it will be difficult for delegations to go back to their Parliamentarians, report that the initial offer was not good enough, and ask for a new pledge to be approved. Some stressed that this would not be feasible. Concern was also raised that Parties might discount their pledge to leave room for ratcheting up. However, the opposite effect is also conceivable, as expected scrutiny might discipline Parties to make defensible first offers.

Past experience with reviews under the convention provides a lesson that a clear plan is crucial and that the process must not be too costly or time consuming.

\section{Sequencing}

Should we aim for agreement on architecture before putting numbers on the table? The issue of timing was perceived as highly important. Arguments were made both for a sequential process and for a simultaneous process. In terms of indicators, the question translates into what needs to be in place before Parties submit pledges: a) an agreed set of indicators and numerical values for each country; $b$ ) an agreed set of indicators to guide Parties in proposing pledges; or c) no agreed set but perhaps general guidelines on using indicators.

Supporting a sequential approach, the Berlin mandate was invoked as an example to follow. It provided the structure of the Kyoto Protocol, not just a mandate to negotiate. A similar sequencing would guide Parties to make reasonable first pledges, as Parties will better understand how their pledges will be reviewed. The drawback with sequencing is that the numbers would get delayed, and the process might be held hostage. The time constraint is an argument for a simultaneous process, working on pledges and indicators in parallel. The severity of the time constraint depends on what is to be finished in Paris. Several noted that having first information on pledges ready by 2015, and a review before 2020, might be more realistic than finalizing all commitments in Paris. 


\section{norden}

Nordic Council of Ministers

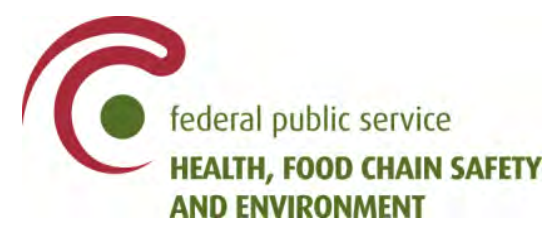

\section{Timing: Warsaw and stepping stones towards Paris and beyond}

Warsaw needs to start the process of proposing commitments, and technical guidelines on necessary upfront information need to be established to ensure that pledges are comparable, transparent, verifiable, and ambitious and to provide a basis for an international assessment/review/consultation. The need for a common target year, facilitating this consideration phase, was invoked. Adaptation also needs to be addressed in Warsaw. In addition, there were calls for Parties to submit proposals for indicators in such an assessment/review/consultation. While agreement on a set of indicators in Warsaw might be unrealistic, one might aim to establish some general guidelines on their use. 